\title{
Sport and Art: a View \\ on the Worldwide and Connecting Area from the Perspective of Sports Science . \\ or: about the Convergence of Two Worlds
}

Authors' contribution:

A) conception and design of the study

B) acquisition of data

C) analysis and interpretation of data

D) manuscript preparation

E) obtaining funding

\section{Rolf Kretschmann ${ }^{\text {A-E }}$, Udo von Grabowiecki ${ }^{\text {A-E }}$}

University of Stuttgart, Germany

\section{ABSTRACT}

The two worlds of sport and art cannot be separated distinctly. Intersections can definitely be identified. Although the discipline "Sport-Art" has not yet been established as a sub-discipline of sport science, sporadic attempts of integration in higher education and academic discussion can be found. In the field of (fine) arts we meet sport in everyday life as so-called practical and commercial art. The fusion is also obvious in the fields of music, art history, and literature. The convergence of the two worlds is clearest in the structural analogy of the genesis of composition, performing arts, literature, and movement products. Finally, a pedagogical postulate is posited that should be understood as a demand for an (school) education that integrates art and sport.

KEYWORDS art, painting, music, ethnology, integrative pedagogy, structural analogy

\section{Preface}

Sport and art are two areas, worlds or spheres, which have approached each other due to interdisciplinary views and ways of thinking as well as differentiation tendencies within sports science branches. About 2,500 years ago, athletes and artists (singers, poets, and sculptors) fought for the same Olympic medals and glory. In a manner of speaking, these two areas belonged together quite naturally, like body and mind. In the Middle Ages, this symbiosis experienced a reversal because of the transformation of religious beliefs, so that the body was degraded (vessel of sin) and the mind became superior. Relics are still clearly evident when one speaks of "hard muscles and soft noggin". This "dog-and-cat-existence" or "catand-mouse-existence" undergoes a very natural symbiosis again through the help of top athletes who have come to the arts, but also through the help of some artists who have approached sport with intensive involvement including movement.

Structurally these two areas are very diverse and culturally they are broadly conceived. The interdisciplinary approach offers and prescribes one to think "outside the box" and to look into other areas. Because the "sport and art" phenomenon has been present throughout all times and cultures of the world, tt is therefore historically and scientifically very interesting and productive. 
The fact that the "satellite" areas of "sport art" and "sport ethnology" do not yet exist officially, as postulated by v. Grabowiecki (1995), can meanwhile be qualified, at least when it comes to sport ethnology. Hence, the libraries of the University of Mainz (Germany) and the University of Koblenz-Landau (Germany) offer a tagging or subcategory "sport ethnology" and scientists like Professor (emeritus) Jürgen Dieckert (University of Oldenburg, Germany) name their research areas with this term.

Concerning sport art, the claim made by v. Grabowiecki has to be renewed. The term is neither listed in the actual edition of the "sports science lexicon" (Röthig \& Prohl 2003) nor in the "fields of theory of sports science" (Haag \& Strauß 2003). But these circumstances should not prevent the following consideration; rather, they should motivate it.

\section{Understanding of the topic}

The term "art" is generally divided into the visual and performing arts. The former ones are usually transitory and gradual, meaning a holistic detection or perception of the whole (such as simultaneous, apprehending listening and seeing) is not possible. In a ballet choreography, symphony or lecture on a poem, we sometimes do not get to know important details, full insight, or content references until just before the end. Visual arts are often static. Architecture, ornament, and pictorial art (painting, drawing, sculpture, relief) is initially available as a whole. A "simultaneous" viewing is possible. Only the expedition of interpretation and judgment cannot be accomplished simultaneously.

"Sport" is an ambiguous term as well. Anyway, this is not the right place to define the term "sport", meaning to exclude what is no longer sport. To get a full grasp on what is meant, it is to be mentioned that pictorial arts often pick out sport scenes as the central theme, which refer to the $18^{\text {th }}$ and $19^{\text {th }}$ century "broader sense of sport" (informal sport, movement in general, play, and physical activity) and display it (children on slides, hiking, dancing, fishing, bathing, and playing with hoops). On the other hand, depictions, which can already or still be called "art", will only be accepted when and because they assume a close definition of art.

Moreover, the theme of this paper ("convergence") is technically not right, because both areas or worlds were originally closely connected, at least from the viewpoint of sport and indeed closer than we know or closer than some people want to believe: for example, at the time of historical Olympic games; during Coubertin's revival of the Olympic ideas; or have a look at the artistic alternation of cold and hot baths until 1948; or 1972 in Munich, when the connection was officially withdrawn, or rather, reset. In the course of history, even more of these interruptions can be found, which show that art is neglected by sport and hardly taken into account. For instance, in Baden-Wuerttemberg (Federal State of Germany), there was a ministry for science and art and another one for cultural affairs and sport. The new distribution still separates sport and art, but the permeability and cooperation is capable of being developed.

It was incomprehensible for the organizers of the "First Juggling Festival in Stuttgart" (April 1991), where there was not only juggling but also leisure sport including competition in about 10 other disciplines in the art of movement, that no money was provided, because the former ministry of cultural affairs and sport was of the opinion that juggling and circus could not be considered sport but was actually art. This might be true for artistic presentations of international stars, but also for many sports of the highest skill level (e.g. trial, motocross, "samba-football", gymnastics, sports acrobatics, aikido, billiards, table tennis, synchronized swimming, figure skating, vaulting, and many more). Everywhere it is shown with and through perfection how a human being becomes a medium of art. But hard and long-lasting motor training is and was the basis in every case. Mass sports activities (playing, practicing, and exercising) in artistic disciplines, as for example juggling with balls, do not really differ from those of a table tennis player who also hits his ball a thousand times more or less precisely to his partner or opponent to win but often just to have fun. What is the difference to an amateur juggler, who does a variety of ball tricks with his partner until it becomes a perfect movement? 
Meanwhile, recent views hold that movement arts also contain a lot of value and worthwhile pedagogy, and only at higher levels does it fulfill one's expectations for art. Particularly with circus movement arts, it becomes clear that the term "art" definitely refers to "skill".

One could connect the terms sport and art in this way as well: "Art in sport", or "sport for art", "art for sport", "sport as art", "sport-art" or "sport-artist". For decades one has talked about sport as the " 8 th art". Thinking in such a connecting way, one can derive an interesting, maybe new and different structure of contents and areas that fuel the wish of cooperation with art academies and to assign topics based on sport. Thus an interesting and real inter- or transdisciplinary cooperation could become reality. By highlighting the various aspects in the sport-art-area, it is important to show which, and how, different genres of art have coped or will cope with the theme of sport at different times and places of the world.

\section{Determination of standpoint}

Basically, sport and (performing and graphic) art make up a small universe: sport and music, sport and poetry/ literature/ language/ theatre, sport and painting/ sculpture/ graphic, sport and caricature/ persiflage, sport and advertisement, sport and choreography, sport and dance (contrast or similarity), sport and circus (also an interesting encounter of two arts), sport and design with additional consideration in different eras, countries and different historical connections. Sport and art are the foundation of a huge quadrature of a circle.

There were and are a few occasional conferences in Europe and Germany: the "Sport and Art" symposium in Leipzig in 1983 and in Mons (Belgium) in 1984, and "Sport and Literature" in Feldafing (an "intercontinental" symposium of the German Association of Sports Science in 1985 and 1988), which was, unfortunately, was cancelled in 1992 due to financial constraints. In addition, the symposium "How Art came to Sport. - Sports from a cultural point of view", which was recently held in Stuttgart. Thus, sport art is still an insiders' tip, sport and art a leisure activity or private "pleasure", yet it always involves a lot of commitment when one thinks of the beautiful accompanying exhibitions at gymnastic festivals (stamps with sporty motifs at the 1987 German Turnfest in Berlin), congresses or the European and World Championships in Athletics. Even oil and watercolor exhibitions of visiting circuses have their own fascination, as well as the three accompanying art exhibitions in Karlsruhe which displayed types of sport that were not yet Olympic in 1988 or the sport-caricature-exhibition in Stuttgart's city hall - "top-class sport with pointed feather" - (Aicher \& Adam 1981), aquarelles with sporty motifs in the "House of Sport" in Stuttgart, over 50 exhibitions in the gallery of the Frankfurter "House of Sport," diverse exhibitions in financial institutions, to name a few regional exhibitions. Ultimately, all of the regional and transregional paint and poster competitions of the youth and of renowned artists have to be mentioned. The relatively large and increasing number of such exhibitions shows that the degree of consciousness and acknowledgement of this beautiful area is increasing. In the 1970s and 1980s, many sport artists met regularly in the Thuringian Bad Blankenburg. The basic ideas were published by Witt (1983) as "conversations" in the journal Theorie und Praxis der Körperkultur (TPKK). In Stuttgart, Genkinger (a painter and graphic artist of many football motifs) was a guest in an academic regulars' table conversation of the Department of Sport and Exercise Science (formerly Department of Sport Science) of the University of Stuttgart. In 1992, the congress "Play, plays, to play" in Tübingen (Germany) offered an interesting exhibition of F. Begov, at which works of art were also shown.

Since 1995, there have been sport-art pictures in the Department of Sport and Exercise Science in Stuttgart. A small percentage of the building sum (2\%) had to be used for "Art at sports facility construction", which can be seen in the decorations. However, small-scale sculptures were placed in the new part of the building, which was built in 2008.

Under the academic hand, there are still many essays about or by artists (painters, sculptors, designers, and graphic artists) who dealt with sport topics - and were top athletes themselves as well: K. Jäger (boxing), E. Stroot (decathlon), U. Hoeneß (football), U. Böbel (handball), A. Aguilar (gymnastics), 
R. Riek (volleyball), T. Cranston (figure skating), etc. There are also many essays about sporty painting, e.g. in the journal Olympisches Feuer (Brucker 1982) as well as in the journal Olympische Jugend (Grasshoff 1987a, 1987b, 1987c, 1987d, 1991). Furthermore, one can find essays that evolved from activities in seminars / workshops, accompanying essays to exhibition catalogues, literature researches, considerations, and thoughts from historical or contemporary epochs and different areas of art, e.g. from Bannmüller (1985), Fischer (1989), Gebauer (1971, 1995), Geßmann (1977), Gillmeister (1986), Gumbrecht (1995), Lämmer (1982, 1986), Lenk (1985), Röthig (1996), Schwaibold and Wieland (1993), Witt (1969, 1982, 1983, 2002), etc. Geßmann (1977) wrote a whole book for schools (Sport - künstlerisch gestaltet). Kühnst (1985) composed a bibliography with more than 3,120 titles and published the article "Sport im Spiegel bildender Kunst" (Kühnst 1992) in the German journal of sport science. Thus, this area is going to be presentable for serious sport-scientific consideration. Kühnst has already enriched some sport events and congresses with exhibitions and therefore immensely supported the development of the thematized area phenomenologically as well as practically or concretely.

\section{Integration into the multidisciplinary "Sport Hedgehog"}

As already mentioned, German gymnastics festivals, World Games, World and European Championships often include art exhibitions. This shows that there has always been a tight bond between art and sport, which will hopefully be maintained in the future. But everything that has been enumerated, all the essays and artists' meetings as well as exhibitions, were almost always only marginal, often unnoticed and without comment, as opposed to being perceived as a professional hobby by colleagues. Maybe it is because "sport art" did not have a chance to be taken seriously and to establish itself as a sub-discipline and a field of research during the time of expansion and independence of natural, social, behavioral, and humane science within the still young science of sport. This is why one still talks about "sport and art" instead of using the hyphenated approach as is done by the other already established "satellite disciplines" about "sport-art" without "and" and hyphen, such as sports psychology, sports sociology, sports ecology (formerly sport and environment), sports economics, sports medicine, sports law, sports management, sports history, sport philosophy, and, especially, sports pedagogy, being the oldest word and content connection with sport, containing its sub-areas such as sports didactics and sports methodology. However, the word combination displays the connection to the related mother science and the underlying understanding of an inter-, multi- or trans-disciplinary and integrative applied science.

The young and new branches or disciplines characterize themselves as not yet established if they are still written with a hyphen and/or no suitable term has been found yet. Thus one still writes for example "Sport-Ecology", "Sport-Economy", "Sport-Philosophy", "Sport-Ethics", "Sport-Aesthetics", (or Aesthetics of Sport) "Sport-Ethnology", "Sport-Semiotics", and "Sport-Politics" (which is about to be renamed SportPolitical Science). There is an interesting English term in our sport-art-area. However, this term only sums up "Sport-Painting" as one of the sub-disciplines: "Sporting Art". It developed during the period of English Romanticism in orientation to Dutch landscape painting and purports to document behavior and movement in sport naturalistically and authentically. Kühnst (1985) also published a "booklet" about "Sporting Art" in the DDR (German Democratic Republic). At this point we can only refer to his thesis in this area (Kühnst, 1994).

These thoughts should light up the awareness level in this inter- or multidisciplinary topic and tell us where and how those areas are organized and what is still missing to structure and open up these new fields and areas without fear of overloading the canon of sports science with another discipline. It seems to be a perfectly normal development of a relatively young, vibrant, and expanding science to allow for something new or to integrate it as an interdiscipline. Thus, the "hedgehog" is to be understood in a maner in which the spikes of this peaceful animal have an alternating influence on the outside and the inside.

For our customers, the students of sport and exercise science, it is important to know that apart from medicine, history, pedagogy, sociology, training, performance, competition and movement theory, there are 
far more than a dozen areas which are important when one deals with the subject "sport" (and movement, etc.) and could be relevant for their future career and in which they should have knowledge even if they do not yet seem to be important for teacher trainees. Besides, there are bachelor's and master's degree programs (formerly master's and diploma courses) for extracurricular activities, for which the (teacher) "self-service store" has never enough "goods", meaning areas, where one can/should/has to help oneself whenever one sees fit to keep up with the times.

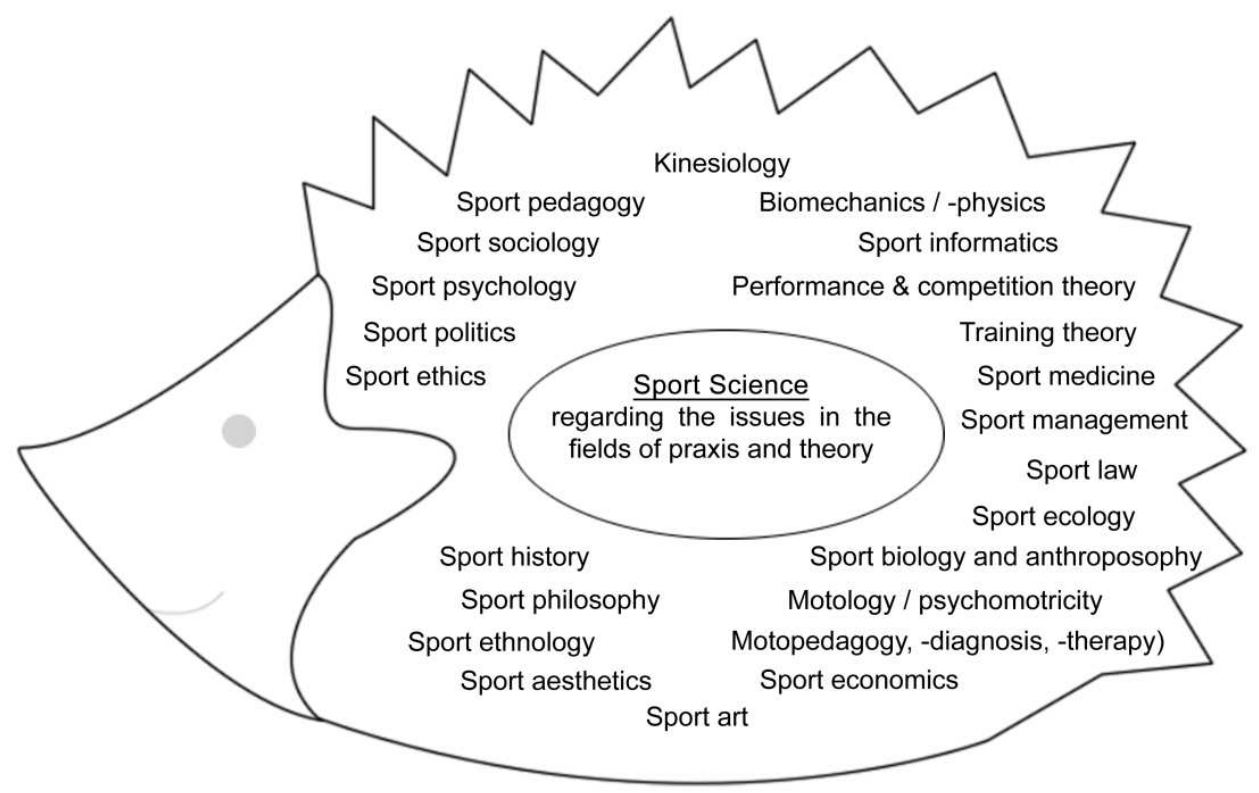

Figure 1. Multidisciplinary Sport Hedgehog

Source: ( v. Grabowiecki 1995).

\section{Everyday life encounter}

Let us go one step further into one of the many content areas and let us ask where we find connections between sport and art in everyday life. For example, we find them in the daily announcement spots on sports programs of all major television channels in public cooperations as well as in private broadcasting organizations. Here again, artists and computer designers were anxious to create their spots with a lot of effort.

Further examples are the beautiful pictures of sport calendars with sporting figures, which moved sportingly to animation spots (TV Channels) in their time. In other calendars and almost daily in newspapers, there are remarkable sport photographs, as well as interesting graphics (as posters/ placards); in other announcements one can see computer animations with smooth, technically brilliant transitions from one sporty activity to another - all neatly related to advertisement.

"Commercial art" includes stamps as well as numerous collections with beautiful sporting motifs. At the Olympic broadcasts of 1988, studio guests received a whole stamp album full with such motifs - a brilliant collection. For almost every important sport event, new stamps are produced in all the main countries. The signal effect to support the informational effect incidentally ("I see, Winter Olympics 1998 in Nagano, Japan") is strong enough because of the almost daily encounter with stamps - and all those charity stamps additionally serve the sport for an immanently good purpose.

Furthermore, "commercial art objects" coins, t-shirts, badges, statuettes and cups have to be mentioned. No less than S. Dalí was obliged to create coins for the Olympic Games. Other, less renowned artists also had great ideas for t-shirt motifs. Sometimes there are small-scale sculptures with typically dynamic-frozen movements of chosen sports in showcases of sports science departments - now also available in Stuttgart. Of course these are often relatively transitory pieces of art, commissioned art, partly 
kitsch (e.g. small-scale sculptures of Greco-Roman wrestlers and discus throwers of Dextro). But usually there were skilled artists who had the ability to create such pieces of art.

For some years, computer design has opened up new "possibilities" for art, even for amateurs. According to the event's importance, amateurs or top artists, graphic designers, or designers are employed whose works - often after a first competition - are honored and used again for announcements and posters. For example, one can think of the many national painting competitions in schools or of European Championships, World Championships, World Cup, and Olympic posters for whose creation internationally renowned artists compete. Also, in various advertisements like video clips, newspaper announcements, TV spots, etc., one comes across very smart and creative, artistically valuable ideas. Eventually, many logos and pictograms, which sometimes offer real successful abstractions of movement, should not be missed. Years ago, the state building association had a nice plaster half-sculpture made as first prize (LBS-Cup Gymnastics).

A further very interesting area is the caricature, which again depicts its own small universe and can be seen and smiled at in newspapers and journals every day. One can generally distinguish pictorial/ graphic/ scenic caricatures from linguistic and (humorous) motor caricatures (skilled persiflage in ballet and gymnastics).

Meanwhile one can name countless books that offer many delightful caricatures. The endeavor of bibliography and listing the artists of national and international caricaturists cannot completely be compared to a life's task but shows enormous effort due to the huge number and therefore cannot be outlined here because of a lack of time. However, it has to be said that a good and meaningful caricature is more and more welcome in loosening up lectures - both from the point of view of students and lecturers. Sometimes the sport caricature was even the focus of a "serious" perspective in seminars at universities (Educational University of Ludwigsburg, Germany, 1984).

\section{Encounter with art in everyday life of sport}

Of course there are striking connections between sports and different areas of art in the "universe" of (competitive) gymnastics and the entire area of dancing, e.g. choreographies of various dance and jazz dance styles or ballet as a whole. These are all disciplines that sui generis include the Artistic, because without it they would be worthless. G. Kohm, from Maulbronn, Germany, is a renowned person in the state theatre of Stuttgart, Germany, who wrote a very interesting book (Tanz des Lebens) in 1993 in which he captured the fascinating world of classical and modern ballet by means of aquarelles, sketches, and drawings (Kohm 1993). Apart from this area of dance, there are a huge number of sports that cannot be performed without aesthetic features, choreography, and artistic expression. Fragmentation of rhythm, time and space, gesture/ facial expression, etc., can be seen as an indispensable part here. Here are some further typical examples:

- Roller skating and figure skating, especially the sub-discipline, ice skating. But also in pair skating, there is the clear effort to "conjure up" the musical message's content even more expressively on ice.

- "Ski figure skating" as a sub-discipline of trick skiing. This term is not (yet) official but is performed, trained, and evaluated similar to ice skating, only on an inclined plane.

- Water ballet or synchronized swimming, in pairs or in larger groups.

- Further examples: rhythmic gymnastics; some sub-disciplines of sport acrobatics; wheel gymnastics; vaulting; step, show, formation and (artistic) folk dance; body building (body as a work of art), break dancing, gymnastics, parachute-figures and formation jumping; circus sport, artistic cycling, capoeira, contact, and improvisation.

In the choreographic disciplines, at least three areas of art are combined: music, movement, and stage or stage design. In a sense, the creation of architectonic impressions can be achieved by means of decoration, light (including special effects), and the corresponding dramatic arts from skillful gestures/ theatric to pantomime techniques. 


\section{Sport and Music}

Sport and music means a number of things, but due to the danger of getting lost, only the three main situations will be dealt with. This includes the when, where, and how music and sport are connected:

- Pieces of music for sport are systematically chosen and used as background music or motivation for ski gymnastics, hip-hop, step aerobics, or on a higher level, as a guideline for competitive exercise in show dancing, ice dancing, for a ballet study, or for formation dancing, etc., where the content of music has to be interpreted in a understandable way. Symphonic poems, elegies, popular pieces of music, etc., such was with Torvill and Dean, who revealed in a hardly attainable manner during an ice dance to Ravel's Boléro in 1984, and which serve as a pattern and need biographic explanation every now and then to let us understand the deeper musical sense. Hymns are used for the glorification of ideals, ideologies, political systems, national peculiarity, e.g., at the beginning of popular sport events. For many Olympic Games, they were composed just for this reason. Composers who were engaged to compose Olympic symphonies, fanfares, hymns and songs, were, for example, K. Orff, W. Egk, H. Genzmer, R. Strauß, P. Winter, G. Frommel, R. Quilter, and H. Rehbein. Similar to painting and literature, renowned composers were therefore also artistically interested and committed to "issues of sport".

- For a (mostly) finished choreography of movement or design idea, a fitting piece of music is cut. Often these are collages, meaning parts of a much longer piece of music or even of different pieces of music, sometimes combined with parts of completely different musical styles. One can see this, for example, in the music of pair-skating on ice, in synchronized swimming, in sport acrobatics, gymnastics, or dance choreographies - right up to a Swan Lake Persiflage of Paul Hunt (former top US gymnast), a particularly beautiful example of humor-motorical caricature. Another alternative of musical application are live piano improvisations of different styles, which are used in ballet training or choreography training in rhythmic gymnastics.

- For professionals, music that fits the respective "sport interpret" with a finished choreography is cut, composed, and arranged belatedly. The shades, fittings, graduations, nuances, tastes, styles, and fashion trends were subject to manifold processes of development and change during recent decades and proceeded unexpectedly, other than planned. This whole network is therefore as complex as music, which tries to express itself with its variety by formal and rhythmic means and displays its whole range of expressional possibilities.

\section{Sport and (art) history}

Considering the manifold, "colorful" aspects of sport historical points of view, one cannot escape the debate about art historical certificates, as sport history is tightly connected to art history. One of the "ancient questions" of sport history is the one about motives that led mankind to do sports, e.g. physical exercises, sporty games, skillful stunts, dances, etc., and in which form and scope they did this "sport". Of course one has to consider everything in the context of that time, meaning not to transfer today's standards on former times.

Further questions arise about the problem of sport forms, meaning what exactly could be considered as sport at that time. Was hunting and dancing, not only important for survival or culturally shaped, but was not there the "urge of art" and ambitious competitive thoughts 7,000 years ago? With certainty, not only at the time of the ancient Greeks. On the other hand, one would have to ask whether some scenes of rock painting, cave painting, or small sculptures from times before Christ could be judged as artistic certificates or only contemporary possibilities to rebuild reality. Then we would have a steady balancing act between art and documentation - similar to today's photography. The historical sport consideration by Tiedemann (2007) has to be mentioned here, which lists and discusses also sport-related works of art. 


\section{Sport and poesy/ language/ literature}

The span of European literature, which has dealt with sport topics, begins with Pindar (Greek lyric around 500 B.C., also composer of lyric choir songs in which verse, music, and dance build a unity). Unfortunately, only 4 of 17 books with odes for prizewinners of Pythic, Nemic, Isthmic, and Olympic competitions have been preserved. There is also medieval verse from knights' festivals and tournaments $(\mathrm{H}$. Sachs). During the early Renaissance, there were many Middle French and Middle English allegorical and emblematic poems about ball games. In 1532, Rabelais described approximately 200 games, skillful activities, and other sporty activities in Gargantua und Pantagruel - similar and comparable to the popular picture of P. Breughel, who depicted no less than 80 games there. Moreover, there are poems about gymnastics by Ringelnatz (1958), to mention only some striking cornerstones, reaching the literature of the pre- and post-war period, from Brecht, Kästner, Wolf, Musil and Elias to Blickensdorfer and Herburger.

One example from a poem about ball games by F. Quarles (1632) in Middle English is representative for many interesting examples:

\section{Man is a Teniscourt: His Flesh, the Wall}

The Gamster's God, and Sathan:

Th' heart's the Ball:

The higher and lower Hazzards are

Too bold Presumption, and too base Despaire:

The Rackets, which our restlesse Balls make flye.

Adversity, and sweet Prosperity:

The Angels keepe the Court, and marke the place,

Where the Ball fals, and chaulks out ev'ry Chace:

The Line's a Civill life, we often crosse,

Ore which, the Ball not flying, makes a Losse:

Detractors are like Standers-by, that bett

With Charitable men: Our Life's the Sett:

Lord, in this Conflict, in these fierce Assaults,

Laborious Sathan makes a world of Faults;

Forgive them Lord, although he nere implore

For favour: They'l be set upon our score:

$O$, take the Ball, before it come to th' ground,

For this base Court has many a false Rebound:

Strike, and strike hard, but strike above the Line:

Strike where thou please, so as the Sett be thine.

The number of works about sport literature since 1949 in the former DDR is considerable. Kühnst (1995), Grasshoff (1987a, 1987b, 1987c, 1987d), and Lämmer (1986) arranged extensive bibliographies in this area.

\section{Structural analogy}

The way or process of the idea and the wish to write, to draw, to write poetry, or to compose something about designing, constructing, building, sorting out, and to achieving an artistic final product run is analogous to the respective other art areas. In other words, there are comparable elements that proceed horizontally and thus on the same intermediate stage on which the developing product finds itself.

A fictive but generally accepted example: vertical (from bottom up) musical piece develops by stringing together specific "letters" signifying the sound names. Then the composer "builds" a special 
sequence; a melody of some beats develops and thus a particular character of the play. Maybe one can already recognize that it is a burlesque, a description of mood or landscape or even fun background music.

But depending on the intention, things could run differently, e.g., a harmonious consonance develops in further beats or parts. With the respective accompanying accords, harmonious connections and through differences, the same or only very special instruments, the composer follows his inner imagination and reaches an overture, a chanson, a symphony, a dancing piece, a lullaby, a hymn, or a folk song. Only with the specific array of sounds, of rhythm, of harmonies and special figural and harmonious arrangement, the composer arrives at his contextual or atmospheric message. With designing, building and cutting of a movie or with working on a sculpture, it is exactly the same.

Let us have a look at the same procedure, e.g. with a poem about sport: at the beginning there are again letters, syllables, words, combinations, lines with content and message. Then we have again references of grammatical and contextual kinds, an atmospheric description or critical undertone discerned; hectic or tranquil silence radiates; glory and glamour are spreading. It is similar with the construction of sport romances and (video-/ TV) films about sport topics with real, fictive, or utopic biographies of athletes. There are interlaced textual, contextual, and partial passages (construction forms) that are referred to each other and also gain validity and effect by means of language, word choice, combination, coloring, style, etc.

In architecture, the analogy could look like this: a fundament is grandiose or, e.g. narrow according to what will be built on top of it; on top of it, there are the respective "letter-elements", meaning the stones, the beams, the strutting, the room arrangement, the asymmetries, the symmetries, outer and inner arrangement of surface and rooms, cable and pipe connections, plaster and inner design that, as a whole, lead to the intended effect. In the end it will be a pleasure castle, a water park, a fitness center or a stadium. Something which leaves behind a special effect and impression that, like the character of a musical play, theatre play or like styles of paintings from particular epochs, affects the observer and cause him to make contrary decisions. These can be/ have to be revealed (e.g. at guided tours) more clearly by a specialist.

The listener, reader, or observer cannot recognize or understand the condensing process of the artist with his individual, sometimes even biographical, symbolism or his own formal stylistic means. Therefore, a linguistic or gestural illustration as well as an allegorical painting from the Renaissance or the Expressionism needs explanation to generate more and complete comprehension.

Pantomime is another important area of movement and art, as well as the interpretation of dances or ballet and ice dance choreographies. They behave exactly the same: let us take a gesture of suggestion as "prelude", which can continue this or that way until it reaches a meaningful, speaking sequence of movement that can reveal feelings or explain a plot context, etc., to express joy or desperation together with the dancing partner through a movement which only displays a simple, requesting gesture. This is maybe followed by a jump, some turns, which are matched to those of the partner in a choreographically planned room arrangement, etc. In the end it is understood that it is all about an invitation to a dance, about a mean temptation or a rebellious fight against any powers or about the trial to display the content of classical musical pieces, like Händel's Messiah, dance-like. The old fight in how far ballet is art or sport, or artistic sport or sporty art is one that everybody has to fight for on his own. In training, the sporty moment is predominant, while at performances it steps back and the artistic pleasure - at least for the spectator outshines everything else. Think of Delibe's Coppélia, Adam's Giselle, Tchaikovsky's Nutcracker and Swan Lake, and many more.

In the end, it is even the same with painting. The analogy: lines range over some "useful" brushstrokes and meaningful and nicely ordered spots or areas of paint, room arrangements, points of view, arrays according to the worth of colors, etc., through to elements of landscape, mountains, trees, etc., and thus get there significance. Usually the whole thing is enriched with a contemporary symbolic that the observer or art historian has to translate and to interpret it and thus make it understandable for us. 
After having done the vertical reflection in every area of art and some direct comparisons to neighboring areas, we now want to go through and compare the horizontal consideration as the counterpart in the other areas of display.

Maybe it becomes clearer when one names the areas of art in a different, more literal way: one could almost draw a line over the building, painting, moulding and drawing art as well as the word, sound, film, photo, theatre are and choreography. Because, as already mentioned, the genesis and completion of a symphony is analogous to the development of a sculpture. The search for forms and structures, like in the writing of a musical piece or theater play, a ballade or an ice dance choreography, takes place in a similar way as, e.g., the search for effective connections, sequences of positions and tricks in circus aerobatics and happens in a way similar to the search for coherence and harmony of movements with pieces of apparatus including possible transitions and connections to further movements that should also match, e.g., atmospheric painting art. One could say even more detailed: the smallest bricks like an element of movement or a gesture of suggestion - initially without worth and message - have their correspondence in the other area of art (e.g. in letters, in brushstrokes, or in a beam); on the next levels, bigger units like syllables, words, verses through to the finished poem, pun, song text or absorbing sport report, sport caricature, Olympia or swimming stadium, erotic duo trapeze acts, or paintings of horse races. Multi-synestheticc effort in the sense of artistic synthesis can be seen from the beginning. The language on one area was sometimes not enough. Therefore, composers used not only diacritic symbols in their scores but added visual to acoustic impressions and sometimes even tactile feelings as well as the perception of taste and smell. Think of the symphony scores of Scriabin or many recorded choreographies, which show these analogies and even need them to leave the deeper feelings in a concrete way for the afterworld. Today's multi-media presentations have similar intentions.

\section{Pedagogical postulate for school, training, and education}

Now something like a pedagogic "bubble" could be pulled over the facts already revealed. Because once one has uncovered this analogy and made the connections, structures can be related in an easier way at least mentally. Creative thinking and creative work start from this point. This synesthesia-phenomenon, meaning the interconnection of more than one sense, has many relics in our language, which give us blatantly obvious hints, especially in onomatopoeia (v. Grabowiecki 1974). But this is also not the right approach to go into this more closely. It is only important to show these connections to pupils in an uncomplicated way - as long as pupils can see a connection. Because for young people these structural borderlines are not yet clear and vehement, especially between the single areas of art. For here, the areas are not separated as much as in the adult world. It is easier for both students and adults to meet the wish to become actively creative when they can draw upon something (Latin: creare) that already contains "something" instead of looking for structural connections that lead to nothing. Structural connections that do not meet direct walls of thought should never be regarded and interpreted apart from each other. Today it should be possible to think, present, or write just phenomenologically about structural analogies without knowing everything about "structure" and "analogy". Also, one neither has to be specialist in architecture, painting or music, nor a theatre artist or genius in filming, to hint at these parallels. Only the recognition of the connections between these areas of life and art should encourage and enable to transfer a lot into the area of teaching. Today's children are especially in need of such a targeted influence of art - educational influence - because nowadays it is only through acoustic and visual overload in the media age that deeper urfeelings can be addressed. Thus, it is still incomprehensible how one can dare to "slash" movement education/ sport and to let musical and artistic education pass as third-class minor subjects. The transfer of possibilities that can be acquired by dealing with these areas and which are given to children, like those of exact listening and analytic comprehension of music, patience, empathy for others' trains of thought, delicacy of feeling for different moods and inner feelings of other and oneself, are profoundly character molding and personality forming features for daily situations in life. One should realize these effects. Just as graduates in sports science talk, lecture and judge about sport pedagogy, sport psychology, sport sociology, 
biomechanics, sport ethics, etc., and their respective didactic subchapters without having studied the respective mother science, authors allow themselves to talk/ write at least phenomenologically about painting, sculpturing, graphics, architecture, music, etc., without having studied every single subject. At least with some pre-understanding and additionally acquired knowledge, one can proceed across interdisciplines by squeezing students of other areas of art to deal with sporting topics within their seminars and to write down their thoughts in one or the other seminar or even in their thesis. It is likely that this has already happened more than once.

A simple introduction at school would be the cooperation with the teacher of German and art with whom one has to talk about the setting for a movement theatre or dancing choreography that is to be constructed by students. Students could also learn a clearly and easily structured jazz, pop, or chanson music with a clear and subtle diagnostic value (musicians or teachers of music should be available as experts) like a jazz dance or the like. One can also get along with simpler means (spray cans or painting tools in connection with tightened linen, suitcase, small apparatuses, daily life items used in different ways, etc.). There should not be any borders for fantasy. The endeavor to proceed in such a way seems to have increased lately - a pleasant development.

\section{REFERENCES}

Aicher, O. \& Adam, B. (Eds.) (1981). Spitzensport mit spitzer Feder. Sportkarikaturen in der Bundesrepublik Deutschland. Ausstellung des Instituts für Auslandsbeziehungen /Elite Sports with Sharp Feather. Sport Caricatures in the German Republic/. Stuttgart: Institut für Auslandsbeziehungen/ Institute for Foreign Relations.

Bannmüller, E. (1985). Ästhetische Aspekte des Bewegungshandelns /Aesthetic Aspects of Human Physical Activity. DVS-Protokolle/ DVS Protocols/, 18, 269-274.

Brucker, O. (1982). Die Stunde des Siegers /Chariots of Fire/. Olympisches Feuer /Olympic Fire/, 32(4), 2-5.

Fischer, N. (1989). Heldenmythen und Körperqualen /Hero Myths and Physical Agonies/. DVS-Protokolle /DVS Protocols/, 37. Clausthal-Zellerfeld: DVS.

Gebauer, G. (1971). Der Sport in der Kunst - die Kunst im Sport/Sports in Art - Art in Sports/. Sportwissenschaft /German Journal of Sport Sciencel, 1(1), 75-84.

Gebauer, G. (1995). Oralität und Literalität im Sport. Über Sprachkörper und Kunst /Orality and Literacy in Sport. About Linguistic Body and Art/. In V. Gerhardt \& B. Wirkus (Eds.), Sport und Ästhetik /Sport and Aesthetics/ (pp. 1529). St. Augustin: Academia Verlag.

Geßmann, R. (1977). Sport - künstlerich gestaltet/Sport - Artistically Designed/. Düsseldorf: A. Bagel Verlag.

Gillmeister, H. (1986). Ballspielgedichte des Spätmittelalters und der Renaissance /Ball Game Poems of the Late Middle Ages and the Renaissance. In N. Fischer (Ed.), Sport und Literatur /Sport and Literature/. DVS-Protokolle /DVS Protocols, 23. Clausthal-Zellerfeld.

Grabowiecki, von U. (1974). Verfahren der Onomatopöien im Französischen, Spanischen, Portugiesischen (Italienischen, Rumänischen). Ein Sprachvergleich (Übersetzungsvergleich)/Procedure for Onomatopoeias in French, Spanish, Portuguese (Italian, Romanian)/. Tübingen: Loseblattsammlung /Loose Leaf Edition/.

Grabowiecki, von U. (1995). Sport und Kunst - Zwei Welten, die sich auch sportwissenschaftlich immer näher kommen /Sport and Art - Two Worlds that Sport Scientifically Converge More and More/. In Institut für Sportwissenschaft der Universität Stuttgart /Department of Sport and Exercise Science at the University of Stuttgart/ (Ed.), Sport: Trainierien - Gestalten. Festschrift zum 60. Geburtstag von Prof. Hans Wieland /Sport: Practicing Designing. Festschrift to the $60^{\text {th }}$ Anniversary of Prof. Hans Wieland/ (pp. 249-280). Hamburg: Czwalina.

Grasshoff, K. (1987a). Eberhard Stroot: Ein Sportler, der Künstler wurde /Eberhard Stroot: An Athlete Who Became an Artist/. Olympische Jugend /Olympic Youth/, 32(10), 19.

Grasshoff, K. (1987b). Hans Borchert: Vom Zeichnen sportlicher Bewegungen /Hans Borchert: About Drawing Athletic Physical Activity/. Olympische Jugend /Olympic Youth/, 32(11), 18-19.

Grasshoff, K. (1987c). Hans Ticha: Sportkunst in der DDR. Notizen zu einer Ausstellung/ Hans Ticha: Sporting Art in the German Democratic Republic. Olympische Jugend /Olympic Youth/, 32(12), 18.

Grasshoff, K. (1987d). Karl-Henning Seemann: Plastiken mit Spiel- und Sportmotiven/ Karl-Henning Seemann: Sculptures of Game and Sport Motifs. Olympische Jugend /Olympic Youth/, 32(3), 18-19.

Grasshoff, K. (1991). Turnkunst von Andreas Aguilar/ Art of Gymnastics by Andreas Aguilar. Olympische Jugend /Olympic Youth/, 36(1), 18-19. 
Gumbrecht, H.U. (1995). Lob de Sports /In Praise of Athletic Beauty/. Frankfurt am Main: Suhrkamp.

Haag, H. \& Strauß, B. (Eds.). (2003). Theoriefelder der Sportwissenschaft /Areas of Theory in Sport Science/. Schorndorf: Hofmann.

Kohm, G. (1993). Tanz des Lebens /Dance of Life/. Stuttgart: Hirzel.

Kühnst, P. (1985). Bibliographie Sport und Kunst. Gymnastik, Exerzitien, Leibesübungen, Körperkultur, Turnen, Sport und Spiele in der bildenden Kunst von der Renaissance bis zur Gegenwart Bibliography of Sport and Art, Gymnastics, Religious Exercises, Sport and Games in Fine Arts from Renaissance to Present Age/. Köln: P. Kühnst.

Kühnst, P. (1992). Sport im Spiegel der Kunst /Sports Reflected by Art/. Sportwissenschaft /German Journal of Sport Sciencel, 22(4), 401-417.

Kühnst, P. (1994). Zur Figuration des sportiven Bewegens und Verhaltens im Spiegel der Kunst. Eine sporthistorische Untersuchung von der Renaissance bis zur Gegenwart /About the Figuration of Athletic Physical Activity and Behavior Reflected by Art. A Sport Historical Investigation from Renaissance to Present Age/. Unpublished Habilitation Thesis, Ruhr-University of Bochum, Germany.

Lämmer, M. (1982). Sport und Kunst in der griechischen Antike/ Sport and Art in Ancient Greece. In Koordinierungsbüro Deutsches Sportmuseum Köln/ Coordination Bureau of the German Sport Museum in Cologne (Ed.), Bronze und Stahl. Edith Peres-Lethmate. Eine Ausstellung des Deutschen Sportmuseums Köln /Bronze and Steel. Edith Peres-Lethmate. An Exhibition by the German Sport Museum in Cologne (pp. 22-31). Köln: Koordinierungsbüro Deutsches Sportmuseum Köln/ Coordination Bureau of the German Sport Museum in Cologne.

Lämmer, M. (1986). Sport und Kunst in der griechischen Antike/ Sport and Art in Ancient Greece. In Galerie der Stadt Stuttgart (Ed.), Kunst und Sport. Malerei, Graphik und Plastik des 20. Jahrhunderts in Baden-Württemberg /Art and Sport. Paintings, Graphic Art and Plastics of the $20^{\text {th }}$ Century in Baden-Württemberg/ (pp. 21-28). Stuttgart: Edition Cantz.

Lenk, H. (1985). Die achte Kunst. Leistungssport - Breitensport /The Eighth Art. Professional Sport - Popular Sport/. Osnabrück: Edition Interfrom.

Quarles, F. (1632). On a Tenis-court. In F. Quarles, Divine Fancies (The third Booke, 37). London: M.F. for Iohn Marriot.

Ringelnatz, J. (1958). Und auf einmal stand es neben mir. Gesammelte Gedichte /And Suddenly It Was Right Next to Me/. Berlin: Henssel Verlag.

Röthig, P. (1996). Sport und Ästhetik /Sport and Aesthetics/. In H. Haag (Ed.), Sportphilosophie. Ein Handbuch /Sport Philosophy. A Handbook/ (pp. 209-228). Schorndorf: Hofmann.

Röthig, P. \& Prohl, R. (Eds.) (2003). Sportwissenschaftliches Lexikon /Sport Scientific Dictionary/. Schorndorf: Hofmann.

Schwaibold, F. \& Wieland, H. (1993). Im Abseits des literarischen Marktes /Aside the Literary Market/. Olympische Jugend /Oylmpic Youth/, 38(1), 12-14.

Tiedemann, C. (2007). Sport-Bilder - ihre Bedeutung für Sport-Historiker /Sport Images - Their Meaning for Sport Historians/. In B. Kratzmüller, M. Marschik, R. Müllner, H.D. Szemethy \& E. Trinkl (Eds.), Sport and the Construction of Identities. Proceedings of the XI International CESH-Congress, Vienna, September 17-20, 2006 (pp. 819-829). Wien: Turia + Kant.

Witt, G. (1969). Sport in der Kunst /Sports in Art/. Leipzig: Seemann Verlag.

Witt, G. (1982). Ästhetik des Sports. Versuch einer Bestandsaufnahme und Grundlegung /Aesthetics in Sport. Attempt at Inventory Taking and Foundation/. Berlin: Sportverlag.

Witt, G. (1983). Kunst und Sport in der DDR - Gemeinsamkeiten ihres Beitrages zur allseitigen Entwicklung sozialistischer Persönlichkeiten /Art and Sport in the German Democratic Republic - Commonalities of their Contribution to the Holistic Development of Socialistic Personalities. Theorie und Praxis der Körperkultur /Theory and Practice of Physical Culture/, 32(12), 883-888.

Witt, G. (2002). Bewundert, geschmäht - auch vergessen? Malerei, Grafik und Plastik der DDR zum Thema Sport /Admired, Vilified - and Forgotten? Paintings, Graphical Art, and Plastics in the German Democratic Republic on the Topic of Sports/. Beiträge zur Sportgeschichte /Contributions to Sport History/, 15, 18-31.

AUTHOR'S ADDRESS:
Rolf Kretschmann

Department of Sport and Exercise Science

University of Stuttgart

Allmandring 28

D-70569 Stuttgart

Germany

Email: rolf.kretschmann@inspo.uni-stuttgart.de 